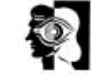

columns

\section{Ian Charles Atichison Martin}

\section{Formerly Consultant Psychiatrist, Darlington Memorial Hospital}

Ian Martin died on 7 November 2006 after a long illness. In his later postretirement years he had become almost a recluse, living in Darlington, a single man with but a housekeeper to see to his needs.

lan died at the age of 72 . Born in Nuneaton in the '30s, and an only child, he never married. He attended Wolverhampton Grammar School before entering Leeds University Medical School where he graduated MB ChB in 1958. After a spell of National Service during which he was posted to Netley Hospital, the Army psychiatric unit in Southampton, he obtained a post in Leeds, obtaining his DPM and FRCPsych in 1978 and working with Professor Max Hamilton, before obtaining a consultant post at Darlington Memorial Hospital. He was a founder member of the Royal College of Psychiatrists in 1971, and later acquired the certificate of the Society of Medical and Dental Hypnotists. His main interest was in the use of relaxation therapies for the treatment of neuroses. He published a book Art and Practice of Relaxation (Teach Yourself Books, 1977) and a tape on relaxation through hypnotherapy, both of which were well received.

lan enjoyed travelling to overseas conferences. We first met during National Service at Netley Hospital and formed a lifelong friendship, travelling together to meetings as far afield as Hawaii, Osaka in Japan, Athens and Mexico City. Ian will be missed.

M. T. Haslam

doi: 10.1192/pb.bp.107.015776

\title{
reviews
}

\section{Reading about self-help books on cognitive- behavioural therapy for anxiety disorders}

Cognitive-behavioural therapy (CBT) emerged in the 1970s and '80s as an imperfect amalgam of cognitive and behavioural therapy, and is by its very nature a changing entity. Today it means something very different than it did a generation ago. Alongside the development of CBT has been the change in self-help books that use CBT principles. Books concerned with the treatment of anxiety are a prime example of this evolution. There is now a huge range of self-help materials to choose from, and both service users and professionals can find the choice overwhelming. Here I select some of the more pertinent, popular and helpful publications. First I describe some data from service users which provide their perspective, then I describe the properties of a good self-help guide and give some examples. I end with recommendations for further relevant self-help resources.

\section{Readers' survey}

I contacted No Panic, an organisation for people with anxiety problems, to ask for feedback from members on self-help guides for anxiety. They were asked to list the books they had used, describe their good and bad points, and to rate several statements that reflected attitudes towards self-help guides. Eleven members of the organisation completed the exercise. Clearly with such a small sample size, their responses might not be indicative of the population as a whole, but they provide initial insights into the perception of self-help materials by people with anxiety disorders.
What was first evident from this small study was the number of guides that were mentioned -24 in total. Only a few books were cited by more than one person, whereas an assorted range of diverse books were only encountered by one person each. The three most commonly read books in this sample were Simple, Effective Treatment of Agoraphobia $(1977,1995)$ and Self-Help for Your Nerves $(1962,1995)$, both by Claire Weekes and Feel the Fear and Do It Anyway! by Susan Jeffers $(1988,2007)$. Claire Weekes' books have clearly stood the test of time as they received almost exclusively positive comments from readers who described her as an experienced, compassionate and helpful writer, although some expressed a reservation that her style was somewhat out of date. Susan Jeffers' book was also positively received in general, but some found the style to be too eager, with often unrealistic examples targeted towards an American audience. Some of the assorted 'gems' cited by individuals received glowing reviews. Examples were Beyond Fear by Dorothy Rowe (2002), Fears, Phobias and Panic by Maureen Sheehan and In Stillness Conquer Fear by Pauline McKinnon (1987, 2000). The books that received negative comments in this survey tended to be the more academic self-help books that were regarded as too distant and included unnecessary information, for example Living with Fear by Isaac Marks $(1978,2005)$

From the survey it was possible to identify the key positive and negative properties of self-help guides (Box 1).

The statements on attitudes towards self-help guides also shed light on the readers' approach to these books. In order to analyse responses, a rating of $50 \%$ or more was counted as an endorsement of the statement. Of the 11 readers, 9 believed that 'No self-help guides are perfect, but I can gain something new
Box 1. Positive and negative points of self-help guides

Positive points

- Easy to read

- Really understands with compassion

- Encouraging and optimistic

- Up-to-date information and style

- Explained why avoidance makes things worse

- Section on building assertiveness

- Practical steps provided

- Realistic

- Helps me understand myself

- Helps me realise I am not going mad

- Author identifies with the reader as a normal human being

- Can easily 'dip in'

- Helps me to soothe myself

- Includes real vignettes or interviews

- Author has been through anxiety

- Useful medical information

Negative points

- Patronising, impersonal or distant

- Only applies to a small range of anxieties

- Goals for the reader are not relevant to me

- Too basic

- Too'spiritual'

- Too much irrelevant information

- Need to already be on the road to recovery for this to be helpful

- Dwells on the symptoms so much that I imagine that I have them

- Not personalised to my difficulties

- Unconvincing case examples

form each one that I read.' Nevertheless, 6 of those surveyed endorsed the statement 'I am on the look-out for a self-help guide that will provide me with the perfect answer to all my problems'. This shows a mixed pattern of expectations of what a self-help guide can offer. Consistent with the professional view of the role 
of self-help guides, 9 people endorsed the belief that 'The most important thing about a self-help guide is seeing it through and putting into practice what it says', which is encouraging. Nevertheless, there were concerns about real barriers to change. Four of the readers stated that 'If I were to recover after using a self-help guide, people close to me would not be able to cope with the change.' Six stated that 'Self-help guides are always going to be directed at the average person with a phobia, so they could never help me with my very specific, personal problems'. This represents a key dilemma in producing a self-help book - how to present general principles yet maintain a personalised approach. Overall, these statements seem to reflect an acknowledgement of the limitations of a self-help book while maintaining hope that new information can be found and used to further aid recovery.

The feedback from the survey indicates that good self-help books have some of the qualities that one would expect from a good cognitive-behavioural therapist compassion, accessibility, increasing understanding, and providing practical, realistic steps to help face fears. It may be helpful at this stage to state the principles of contemporary CBT to clarify this convergence. It is worth noting that contemporary CBT is now both broader in scope, incorporating humanistic principles and close integration with basic biology, and more detailed in its application, targeting key cognitive processes that maintain anxiety. Yet, in essence CBT still has the same guiding principles, which, arguably, any good self-help guide would follow.

- Clinical anxiety is on a continuum with the 'normal anxiety' that all of us have experienced.

- The origins of anxiety disorders are not simple and they vary widely between individuals. Yet, they can be understood when considering a person's temperament, their culture and their life experiences.

- Although health professionals can provide information and support, it is the individual's own responsibility to change - thus, even one-to-one CBT could be considered as a form of 'selfhelp'.

- The sources of a person's fear can be faced gradually by breaking them down into manageable 'chunks' - the essence of 'graded exposure'.

- When a person faces their fears, it is important that they focus on their experience. Today this is often described as a 'mindful' approach - the person is encouraged not to try to control their feelings and thoughts, but to face the experience as it is, in the here and now, in the present without trying to control it. In this way, the individual can acutely perceive what is going on, and then update their beliefs about what is dangerous, and gain increased confidence in the process.

- It is becoming increasingly evident that people with anxiety disorders, just like those with depression, have an 'inner dialogue' or tendency for 'recurrent thinking' that is very negative and undermining towards themselves, sapping away their confidence to face their fears. Learning to notice this tendency and replacing it with more compassionate ways of 'talking to oneself' seem to be very important in the long term.

\section{Recent useful self-help books}

In my opinion, there are only certain published books that have all, or most, of the above qualities. In addition to the popular books by Claire Weekes and Susan Jeffers, described earlier, I would recommend the following recent guides:

- Bemis, J., \& Barrada, A. (1994) Embrace the Fear: Learning to Manage Anxiety and Panic Attacks. Hazelden. This book provides a good combination of personalised accounts and plans for action. It also emphasises the 'inner dialogue', helping people to build up more 'self-nurturing' ways of thinking.

- Kennerley, H. (1997) Overcoming Anxiety: A Self-Help Guide Using Cognitive Behavioural Techniques. Robinson. This is probably the most representative of CBTas it is generally practised in the treatment of anxiety disorders, and includes many useful tables, charts, diagrams and explanations.

- Leahy, R. (2006) The Worry Cure: Seven Steps to Stop Worry from Stopping You. Piatkus Books. This book sounds more 'gung-ho' than it really is - written by a leading American advocate of CBT, it provides a comprehensive coverage of the most recent cognitive-behavioural approaches to anxiety.

- Kabat-Zinn, J. \& Brantley, J. (2003) Calming Your Anxious Mind: How Mindfulness and Compassion Can Free You from Anxiety, Fear and Panic. New Harbinger Publications. This is clearly a more'new-wave' CBT book that focuses on strategies of mindfulness and building up compassionate selfdialogue.

- Cartwright-Hatton, S. (2006) Coping with an Anxious or Depressed Child. Oneworld Publications. This book provides an up-to-date approach to helping parents of anxious children. Often, both parent and child can both learn to cope better with anxiety by learning how to face very simple childhood anxieties.

It can be difficult to recommend the 'right' book to patients when so many tomes are on offer. Some, such as Claire Weekes' Hope and Help for Your Nerves and Passing Through Panic, are available as audiotapes, which some people will prefer. The important thing is probably not the exact book, but getting the patient started on self-help in the right way. It was evident from the survey that most people expected to draw self-help information from multiple sources. At the start they can begin to realise that there is a way that they can cope better with their anxiety and start to overcome its impact on their lives. This approach needs to be tempered by an awareness that it may take time, and will need to be under the patient's own control.

\section{Further self-help resources}

What a self-help book does not provide is the capacity to listen and understand in a respectful and thoughtful way - before action comes understanding. For many people, it is their search for this experience that is most difficult. Clearly, any mental health professional can provide this to the best of their ability and resources, but further improvement may need to come from either one-to-one therapy or from the more established organisations and service user groups. There are many sources of help and information of this kind, as any internet search will reveal. However, some of the highest quality sources are given below.

- http://psychology.iop.kcl.ac.uk/cadat is the website for the Centre for Anxiety Disorders and Trauma which was pioneered by Professors David M. Clark, Anke Ehlers and Paul Salkovskis. It provides information on anxiety disorders and phobias and sources of support and therapy. The centre regularly conducts controlled trials that may be suitable for patients with certain anxiety disorders.

- http://www.fearfighter.com is the website for FearFighter, an online site for computer-assisted cognitive therapy.

- http://www.babcp.com is the website of the British Association for Behavioural and Cognitive Psychotherapies, which is responsible for accrediting CBT courses and practitioners. It also provides information leaflets and a 'find a therapist' page.

- http://www.nopanic. org.uk is the website of No Panic, a service users' organisation. The site includes a great deal of information as well as offering 
telephone-assisted therapy and a welldesigned CBT treatment pack.

columns

- http://www.phobics-society.org.uk is the website of the National Phobics Society which provides direct service user support and information.

The provision of online self-help materials is an exciting advance and these materials are likely to develop into more advanced and popular formats in the future. The evidence base is emerging that they can be a successful, cost-effective medium for delivering treatment. However, use of the internet and television programmes are likely to have a more widespread positive effect on our cultural attitudes to anxiety, and the mental health profession will need to adapt as service users become increasingly vocal and empowered.

\section{Acknowledgements}

I thank members of No Panic for their contributions to the survey described in this article.

Warren Mansell Lecturer in Psychology and Clinical Psychologist, School of Psychological Sciences, University of Manchester, Manchester M13 9PL, email: warren.mansel|@manchester.ac.uk

\section{miscellany}

\section{Online surveys of College membership}

The pace of change in mental healthcare is increasing and the College must remain an influential voice in

determining the direction of that change. If it is to properly represent the views of psychiatrists, the College needs an open channel of communication with its members. For this reason, the College will shortly launch an initiative to use online surveys to improve dialogue on key policy and practice issues.

College members will be invited to join an online panel of psychiatrists who will be asked to share their opinions and perspectives on a range of issues, through the use of brief surveys. In particular, it is hoped that the initiative will reach those members who do not participate actively in other mainstream College activities, and that this will give the College a better understanding of the values, beliefs, experiences and practices of the psychiatrists that it represents. The survey results will be used to inform and develop College policy and as information that underpins its lobbying and related activities.

The number of surveys will be limited and the College is exploring the use of incentives to encourage and reward participation. Adopting an online approach will provide members with a convenient and flexible means of communicating directly with the College. Further, aggregate survey results will also be shared on the College website, allowing members to gauge the values and practices of the wider membership.

We hope that the membership will support this initiative and will share the view that this online dialogue will give the College a more informed and authoritative public voice.

Chris Fitch Research Fellow, College Research and Training Unit, Standon House, London E1 8AA, email: cfitch@cru.rcpsych.ac.uk 